\title{
Regularities in the transformation of coastal and accumulative forms of sea bottom relief, with application for water management
}

\author{
Borys Kapochkin \\ Odessa National Academy of Telecommunications, Kuznechnaya Street 1,65029 Odessa, Ukraine, e-mail: tsb1@ukr.net
}

Natalia Kucherenko, Margaryta Kapochkina

Odessa State Evnironmental University, Lvivskaya Street 15, 65016 Odessa, Ukraine

\begin{abstract}
Investigate the processes of formation of accumulative forms of sea bottom relief and coast. The coincidence of the linear parts of the accumulative sea bottom relief with the direction of tectonic faults. Provides examples exploring the coast of the Atlantic Ocean, the Baltic, Black and Azov Seas. Consider the problem of continuing in the sea geological structures on dry land. On the example of the Azov Sea it was shown that the horst on land in the coastal zone is shown a linear zone of eroded beaches. Sustainable shore erosion are confined to the gorst. Graben on land continues at sea accumulative forms of type foreland. The accumulation zone of sediment are confined to grabens. Shown that different direction storms form accumulative relief in accordance with clear rules. Random exogenous factors are controlled regularities endogenous processes. Endogenous formation of sea bottom relief happens resulting impact endogenous processes on the speed currents. In those locations where currents slows down the sand falls to the bottom. Decrease in speed currents occurs lengthwise tectonic faults. Faults is the migration path lithospheric fluids.

To elucidate the reasons for the formation of specific conditions sediment load was carried out mathematical modeling of currents over a linear zone submarine groundwater discharge.

Hydrodynamic software decides system of Navier-Stokes equations. Made mathematical modeling the interaction currents and the water flowing from a tectonic fault.
\end{abstract}

Keywords: accumulative form sea bottom relief, coast, submarine groundwater, tectonic fault

Submitted 10 April 2014, revised 12 January 2015, accepted 12 January 2015

\section{Introduction}

The coastal zones of oceans and seas are under the continuous influence of exogenous factors. Destruction of the existing shores and the creation of new accumulative forms of seabed relief are carried out by wave processes, currents and, to a lesser extent, by the wind. In connection with the obvious influence of endogenous factors exclusive to the coastal zones of the sea, for a long time it was assumed that changes in the coastal zones of the sea are made by climatic factors. Often, the repetitive wind direction of storms defines areas of the coastal zone that are exposed to the maximum of destruction (Zenkovich 1962).

At the same time, researchers have observed that there is always a clear system, symmetry and harmony in the spatial scales, configuration and orientation of linear areas of the coastline, surface and underwater ac- cumulative forms. In the 60-70s extensive scientific discussion took place about the role of endogenous factors in the formation of seabed relief and the configuration of the coastal zones. However, the mechanisms of influence of "slow" geological processes on seabed relief were not clear. At the same time, the influence of storms on the transformation of the coast and sea relief is not contested. The influence of exogenous factors was considered paramount.

In this paper we study the coastal zone and the bottom topography of the coastal zone of the sea.

The purpose of the study is to show the role of endogenous factors in the formation of the coast and the topography of the coastal zone. Studies were carried out in different geographical areas. This was done to illustrate that the formation of the coast and the sea bottom topography occurs in different geographical areas equally. 


\section{Review of the literature on the transformation of the coast}

In recent years, thanks to the wide application of satellite geodesy, satellite altimetry and satellite interferometry, it has been possible to record rapidly occurring reversible geodeformations of-the surface of the Earth (Uchytel et al. 2008; Mikhaylov et al. 2010a). These processes have not previously been known. New data has made it possible to rethink the results of studies on the dominant role of endogenous processes in the formation of coastal zones. The main provisions of the new theory are presented in (Mikhaylov et al. 2010a). The basis of the theory of endogenous formation of the coastal zones is the result of research on submarine groundwater discharge along tectonic faults. Submarine groundwater creates vertical currents in the water column. Vertical water movement changes the characteristics of the waves and decreases the speed of the current. Along fault zones linear areas of the reduction in the speed of horizontal currents and changes in the speed of orbital waves occur. During a storm, this results in a drop of transported sediment in the flow. Endogenous factors control the exogenous process of sedimentation along the tectonic faults.

Consider the problem of continuing geological structures of dry land into the sea. In the example of the Azov Sea (Klyueva, Furtes 1968) it was shown that the Horsts on land is shown in the coastal zone as a linear zone of eroded beaches. Sustainable shore erosion is confined to the Horst. Grabens extend this foreland into the sea (Klyueva, Furtes 1968). Zones of sediment accumulation are confined to Grabens. A Horst and Graben diagram is shown in Fig. 1.

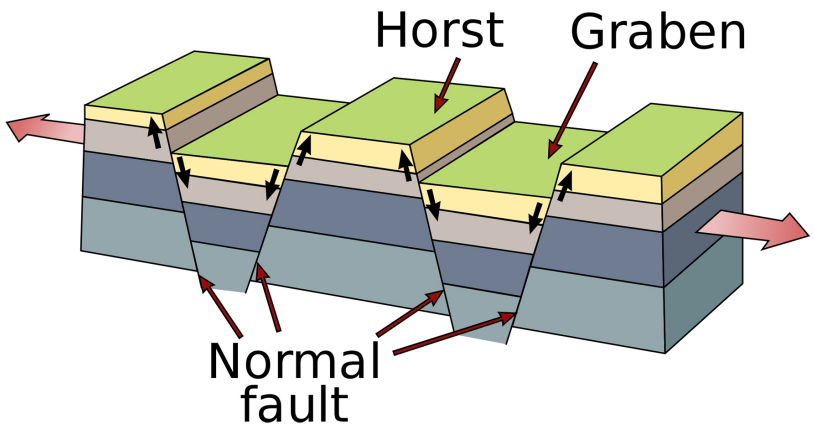

Fig. 1. Diagram of geological structures Horst and Graben

All linear foreland is consistent with tectonic faults. For the Black Sea region this is shown in papers by (Tkachenko et al. 1970).
Publications (Kapochkin, Kucherenko 2006; Kapochkin et al. 2007) form a new research direction in the dynamics of coastal zones. For the first time the mechanism of the influence of tectonic processes on the accumulative seabed relief was considered in (Kapochkin et al. 1998). Data on the move of drifters along the Caucasian coast of the Black Sea was examined. It has been shown that the Black Sea current over tectonic faults in the seabed changes speed and direction. Nearer to fault zones, the speed of its current decreases and the current changes direction. There is movement along the tectonic fault across the main current. When the velocity of the current decreases, the largest particles fall out of the stream.

Estimates of the speed of vertical movement of submarine waters were made in (Mikhaylov et al. $2010 \mathrm{~b}$ ). Speeds of vertical movement of submarine waters can reach $3 \mathrm{~cm} / \mathrm{s}$. For submarine sources located at a water depth of 25 m mathematical modeling was carried out. When modeling, the rate of rise of submarine water was set at $-3 \mathrm{~cm} / \mathrm{sec}$. According to the results of modeling, the submarine waters rose to the surface of the sea (Kapochkina, Mikhaylov 2014).

There are only six systems (Tyapkin 1993) of crustal tectonic faults. In these systems azimuths have $0^{\circ}$ and $270^{\circ} ; 17^{\circ}$ and $287^{\circ} ; 35^{\circ}$ and $305^{\circ} ; 45^{\circ}$ and $315^{\circ} ; 62^{\circ}$ and $332^{\circ} ; 77^{\circ}$ and $347^{\circ}$. The elevated and omitted blocks are located in the "checkerboard" manner and have sizes of $4.4 \times 4.4 \mathrm{~km} ; 8.7 \times 8.7 \mathrm{~km}$; $17.5 \times 17.5 \mathrm{~km} ; 35 \times 35 \mathrm{~km} ; 70 \times 70 \mathrm{~km} ; 140 \times 140 \mathrm{~km}$; $280 \times 280 \mathrm{~km}$. We have analyzed the cartographic material on linearly elongated sandy sea floor structures. If the azimuths of linear accumulative forms and those of tectonic faults match, the deposition of sediment on the sea floor can be explained by endogenous factors.

\section{Results of cartographic research}

As a method of research used in the analysis of linear forms in bottom topography, searches for the conformity of the spatial orientation of linear forms in bottom topography and tectonic fault systems were carried out.

In carrying out the study tectonic maps were not applied. These maps are constructed according to geophysical research. The accuracy of geophysical methods is poor. Maps produced from the results of these methods are not reliable. We use the theoretical 
principles of formation fracture (Tyapkin 1993). This theory is recognized globally.

The processes of the formation of the coast and the bottom topography in the Black, Azov, Baltic and North Seas were studied.

E x a m p le 1. Problems of the shoreline transformation are important for the Netherlands. Fig. 2 shows that the coast of the Netherlands and Germany has a linear form.

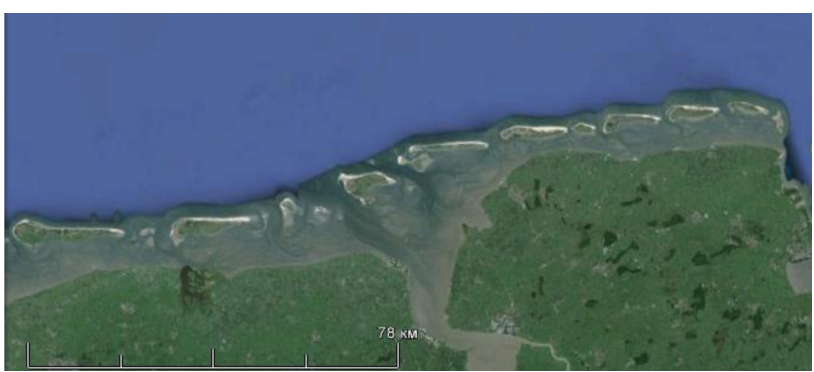

Fig. 2. Satellite image of the coast of the Netherlands and Germany

The general direction of this linear form is about $77^{\circ}$. The sea coastal zone is composed of individual islands. The configuration of the coast and islands is not consistent. These islands are oriented at a direction of about $90^{\circ}$.

Conclusion: The coasts of the Netherlands and Germany are formed with accumulative forms. The general direction differs from the orientation of individual islands. The scale and linear orientation of the islands correspond to the size and orientation of the block crust.

Example 2. In shallow waters of the Azov Sea, there are more than a dozen forelands. Fig. 3 shows that the foreland of the northern coast of the Azov Sea is located at equal angles to the linear coast.

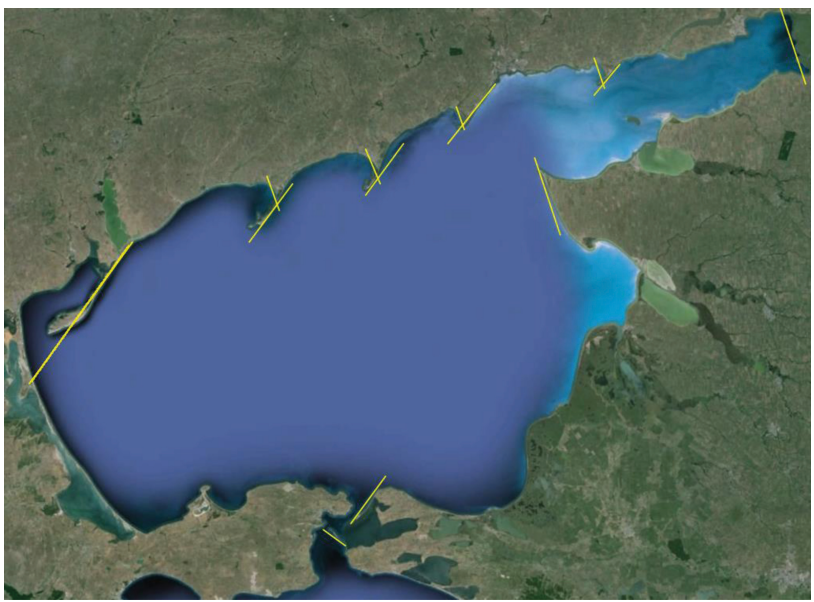

Fig. 3. Satellite image of the Azov Sea. Linear foreland is marked with yellow lines
The general orientation of the northern coastline is $62^{\circ}$. On land, the foreland continues as Grabens (Klyueva, Furtes 1968). They are located along the tectonic faults with azimuths of $35^{\circ}$ and $305^{\circ}$ (Tyapkin 1993). Foreland in the Kerch Strait is formed perpendicular to this foreland.

The outer boundary of the delta of the River Don and the foreland named Long have an azimuth of $332^{\circ}$. The linear foreland is oriented at the same angles. The orientation of the foreland and tectonic faults match. Fig. 4 shows a map of the seabed relief of the Azov Sea.

The map has direct lines, along which the foreland is formed in the coastal zones of the sea. The foreland is shown with a broken line. The orientation of the foreland matches that of tectonic faults. The dashed line of white dots shows linear portions of $5 \mathrm{~m}$ and $10 \mathrm{~m}$ isobaths. Large white dots mark linear portions of the isobaths, the azimuth of which matches the direction of the foreland. It is shown that surface and underwater accumulative relief of the Azov Sea is characterized by common rectilinear structural elements. Their orientation matches that of tectonic faults.

To study lithodynamics of accumulative forms, it is necessary to study the granulometric composition of sediments. Recently intensified geodynamic structures have not yet manifested in the relief. They manifest in a large sand fraction. Fig. 5 shows a map of the granulometric composition of sediments of the Azov Sea.

Green shows the extent of the sand fraction of the upper layer of sediments of the Azov Sea. Sands in the open sea form narrow straight bars in three directions. The three systems of bars are shown with different types of hatching. Underwater accumulative relief is formed exclusively by endogenous factors.

Conclusion: the scale and orientation of surface and underwater accumulative forms correspond to the size and orientation of the block crust.

Example 3. Fig. 6 shows surface and underwater accumulative forms in the Baltic Sea. In the Gulf of Gdansk, the foreland Hel, which is about $35 \mathrm{~km}$ long, is composed of several spits and bars. The continuous line in the figure shows linear portions of accumulative forms with azimuths of $35^{\circ}$ and $305^{\circ}$. The dashed line shows linear portions with azimuths of $77^{\circ}$ and $347^{\circ}$.

Conclusion: the scale and orientation of the linear accumulative forms in the Gulf of Gdansk in the Baltic Sea correspond to the size and orientation of the block crust. 


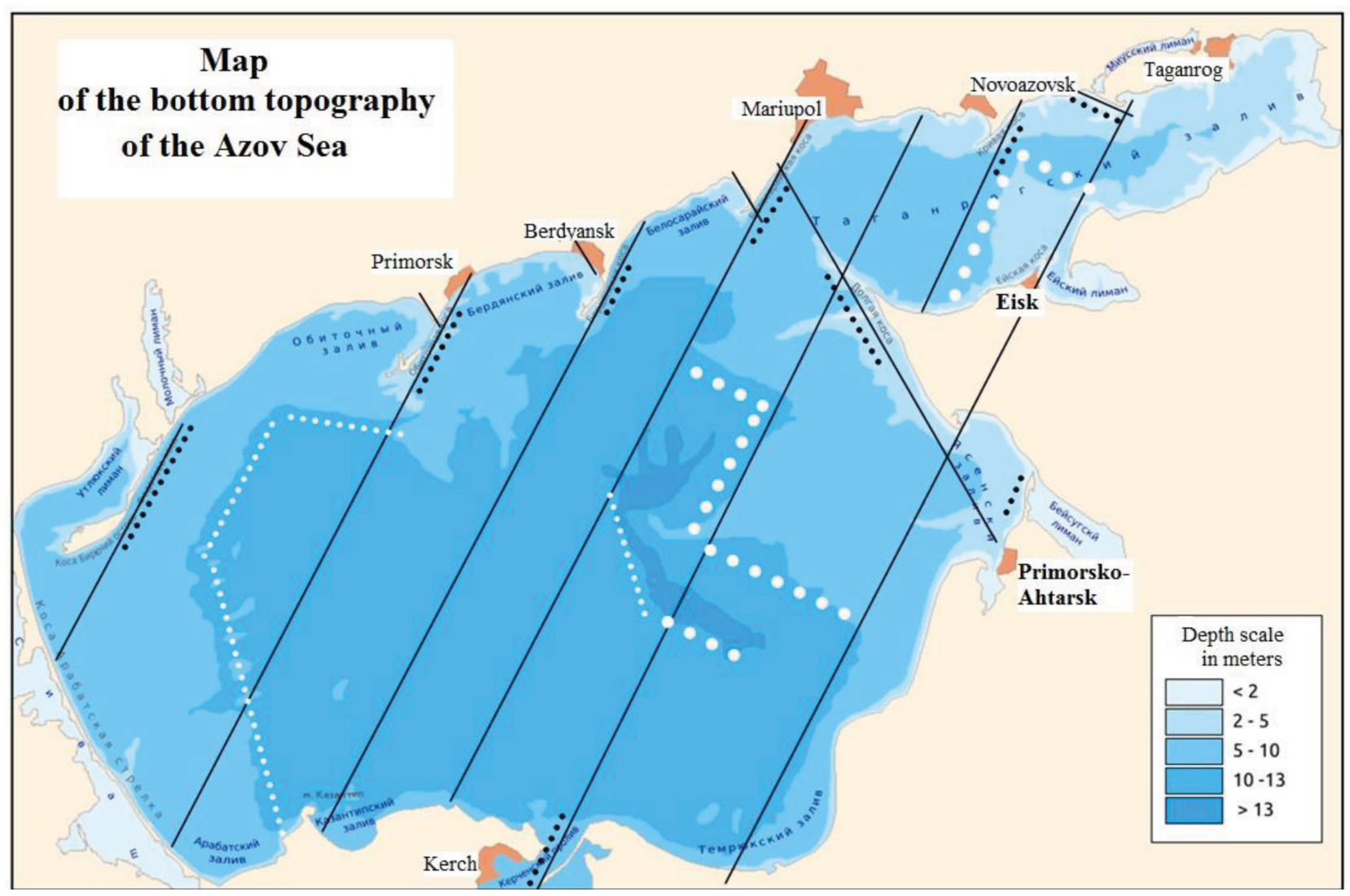

Fig. 4. Scheme of the seabed relief of the Azov Sea. Linear forms of surface and underwater accumulative forms are marked with lines (http://ru.wikipedia.org/wiki/Азовское_море)

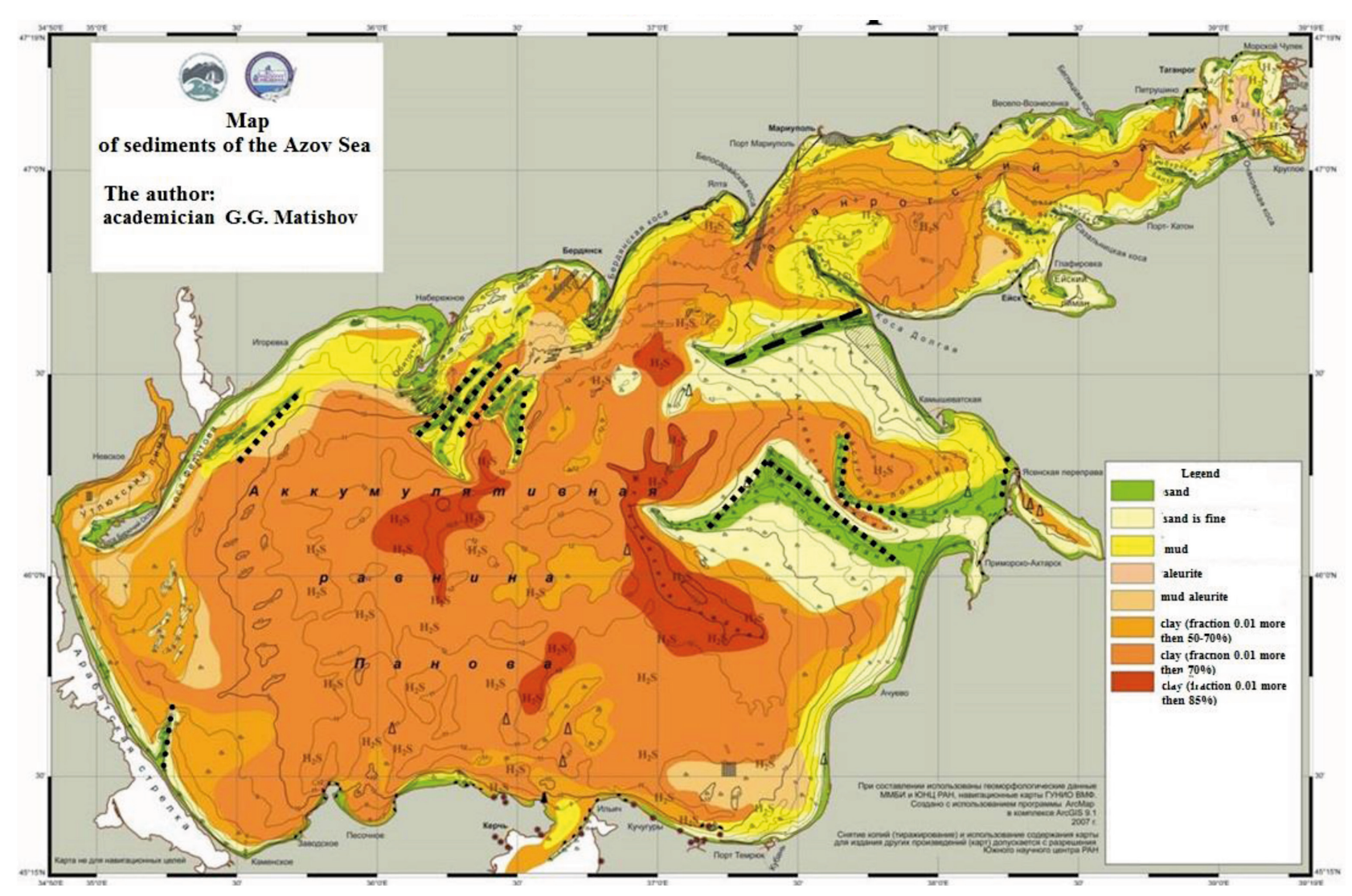

Fig. 5. Map of bottom sediments of the Azov Sea (http://www.ssc-ras.ru/page651.html) 


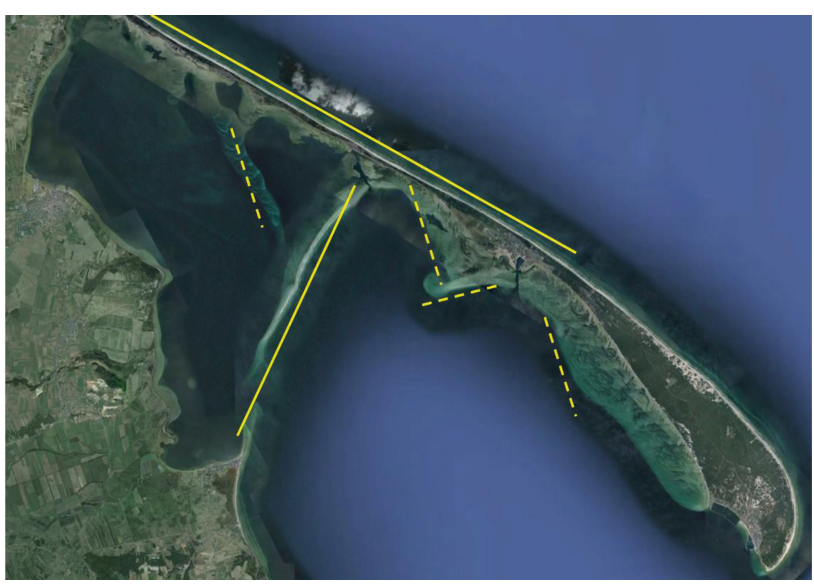

Fig. 6. Scheme of the foreland Hel in the Baltic Sea. Linear accumulation forms are marked with lines

Example 4. Consider the topography of the seabed relief in the north western part of the Black Sea. Here, at the depth of about $15 \mathrm{~km}$, there is a towering Dniester bank with a linear fragment of about 8-9 $\mathrm{km}$ and an azimuth of $347^{\circ}$ (Fig. 7).

The bank height above the bottom is $10 \mathrm{~m}$. This bank has a width of up to $2 \mathrm{~km}$. The northeast edge of the bank is very steep. At a distance of $100 \mathrm{~m}$ there is a change in depth of $10 \mathrm{~m}$.

At a distance of less than $500 \mathrm{~m}$ there is a linear depression with a depth of up to $26 \mathrm{~m}$. The depression azimuth is $17^{\circ}$, and the width is about $2 \mathrm{~km}$. The difference of depth is approximately $20 \mathrm{~m}$. The maximum slopes of the seabed with a depth of $10 \mathrm{~m}$ are at a distance of $250 \mathrm{~m}$ form a linear zone. The length of this zone is about $2 \mathrm{~km}$.

On the top of the bank, conditions for wave erosion are significant. Erosion products of the bank are deposited near it. Near to the bank the formation of depressions had differences in depth of $20 \mathrm{~m}$ and had steep slopes. If such relief is stable, there should be special conditions for sediment load.

\section{The results of mathematical modeling of litho- dynamic processes}

To elucidate the reasons for the formation of specific conditions of sediment load, mathematical modeling of currents over a linear zone of submarine groundwater discharge was carried out.

Hydrodynamic software calculates Navier-Stokes equations. For modeling, the computational domain of a digital model of the seabed relief was created. The computational domain was of $100 \times 100 \mathrm{~m}$. Adesign grid, $1 \times 1 \mathrm{~m}$ horizontally and $0.5 \mathrm{~m}$ vertically, was created. The sea depth of $20 \mathrm{~m}$ was selected. In the center of the computational domain a depression with a depth of $5 \mathrm{~m}$ was set across the current. The depression simulates the linear submarine source of warm groundwater. The set temperature anomaly at the bottom was of $+3.5^{\circ} \mathrm{C}$.

The integral flow rate was set at $1.51 / \mathrm{s} \mathrm{m}^{2}$. The speed of horizontal currents was of $10 \mathrm{~cm} / \mathrm{s}$. Vertical stratification of temperature was $0.1{ }^{\circ} \mathrm{C} / \mathrm{m}$. The visualization of the change in the flow speed is marked with colour, and the direction of the flow is marked with arrows. Fig. 8 shows a vertical section of the flow.

It was established that the discharge of water of a submarine source retards the motion of flows. Vortex zones are formed in front of a linear subma-

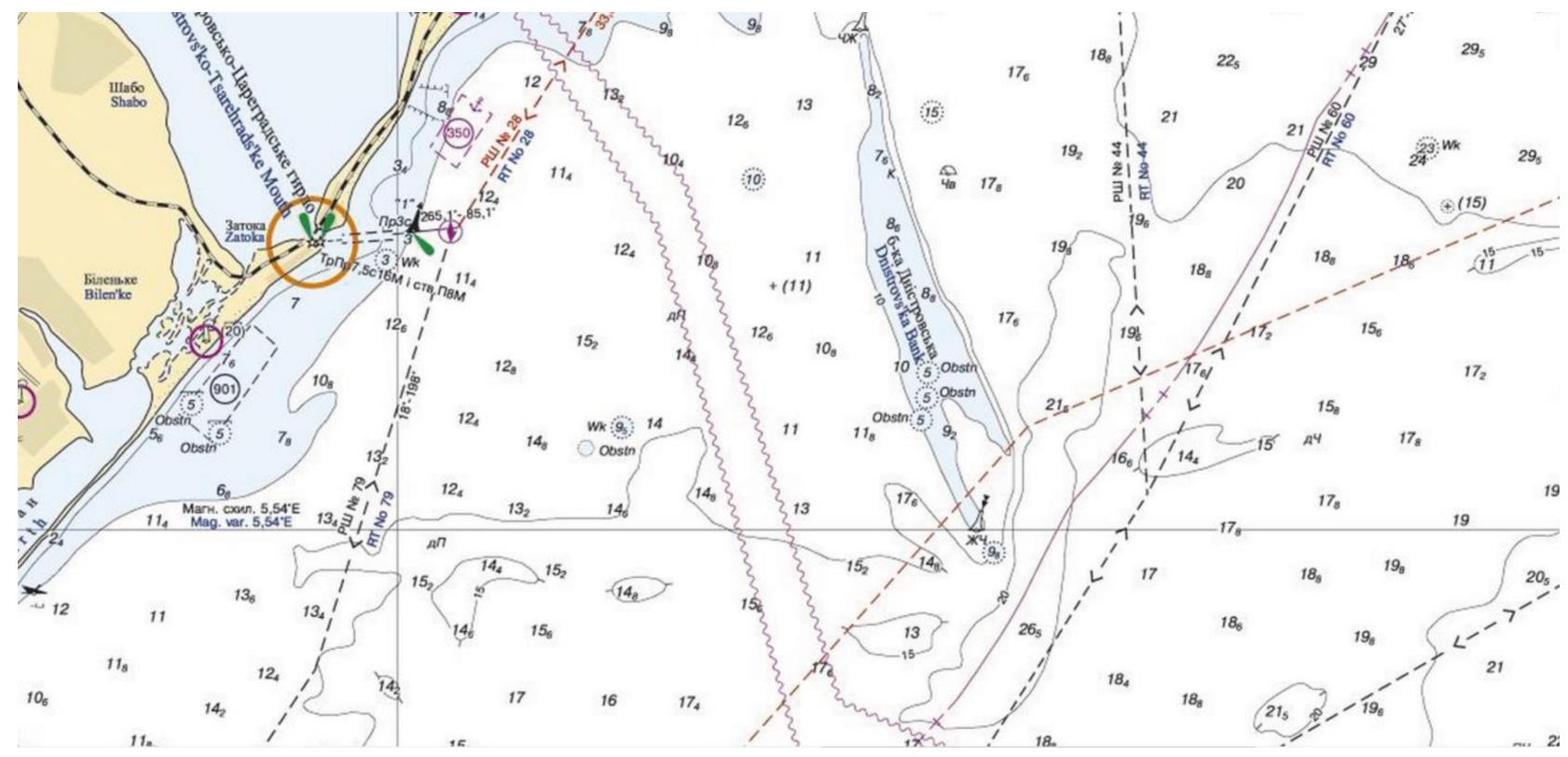

Fig. 7. Fragment of a map of Black Sea depths (http://navytech.ru/Ukraine_coast/31010.html) 
rine source in the flow. The submarine source area is exposed to erosion. A zone of low current speed is formed behind the zone of submarine groundwater discharge. This should be accompanied by falling sediment.

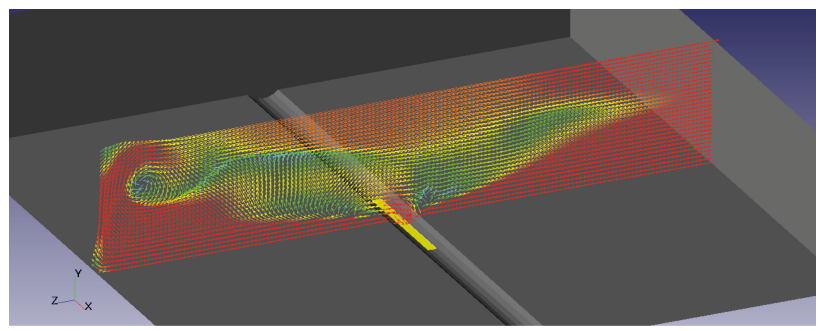

Fig. 8. The results of modeling: interaction of the flow with the vertical flow of groundwater

\section{Conclusions}

Management of marine water resources depends on the size and shape of the water body. It was previously thought that changes in the coastline and seabed relief were formed by stochastic processes. This made it impossible to competently manage water resources. Our studies have shown that winds and currents, obeying the theory of probability, are not able to form the shoreline and underwater bottom topography with distinct spatial patterns. We have established that random exogenous regularities are controlled by endogenous processes. Endogenous processes form the seabed relief due to the transformation of waves and currents. In those locations where currents slow down, the sand falls to the bottom. Transformation in the current speed occurs lengthwise along tectonic faults. According to the tectonic disturbances of the sea bottom, submarine fluids are identified, and they transform currents. The influence of submarine groundwater sources on the sea currents was studied with mathematical modeling.

\section{Bibliography}

Kapochkin B.B., Kucherenko N.V., 2006, The physical model formation accumulative form of the relief of the sea bottom, preprints: EGU - Geophysical Research Abstracts, 8, 02376

Kapochkin B.B., Kucherenko N.V., Isakova J.V., Nagrebetsky V.S., 1998, The geomorphology of shelf and the discharge of submarine fluids, preprints: Littoral-98, $4^{\text {th }}$ International Conference, Barcelona, 265-269

Kapochkin B.B., Pashkina M.V., Kucherenko N.V., Kapochkina A.B., 2007, Influence of tectonic processes on the formation of coast line and accumulative forms of sea-bottom, preprints: $6^{\text {th }}$ International Symposium on Eastern Mediterranean Geology, 2-5 April, Amman, Jordan, 81-82

Kapochkina A.B., Mikhaylov V.I., 2014, Methodology to evaluate the flow of submarine discharge source, $12^{\text {th }}$ International Conference of Students and Young Scientists, PG «Shevchenko Spring», 25-28 March, Kyiv, Ukraine, 43-45

Klyueva V.O., Furtes V.V., 1968, Displaying neotectonic and contemporary crustal movements in the morphology of the northern shore of the Azov Sea, Naukova Dumka, 152 pp.

Mikhaylov V.I., Dorofeev V.S., Yaroshenko V.N., Kapochkin B.B., Kucherenko N.V., 2010a, Modern changes in the level of the Black Sea as a basis for strategy of coastal development, Odessa: Astroprint Publisher, $165 \mathrm{pp}$.

Mikhailov V.I., Kapochkina A.B., Kapochkin B.B., 2010b, Interaction in the system lithosphere-hydrosphere, Odessa: Astroprint Publisher, 154 pp.

Tkachenko G.G., Krasnoshchek A.Y., Pazyuk L.I., Samsonov A.I., Tkachenko V.F., 1970, On the role of the newest disjunctive tectonics on the formation of shoreline morphology of the major areas of the Black and Azov Seas, [in:] Geology of the coast and bottom of the Black Sea and Sea of Azov within the Ukrainian SSR, 24-33

Tyapkin K.F., 1993, Crustal blocks from the standpoint of a new hypothesis of structure formation, Geological Journal, 4, 10-20

Uchytel I.L., Dorofeev V.S., Yaroshenko V.N., Kapochkin B.B., 2008, Geodynamics. Basics of dynamic geodesy, Odessa: Astroprint Publisher, $311 \mathrm{pp}$.

Zenkovich V.P., 1962, Basics of coastal development, USSR Academy of Sciences, $710 \mathrm{pp}$. 